\title{
VARIABILIDADE ESPACIAL DOS ÍNDICES DRIS DO NITROGÊNIO E DO POTÁSSIO NA CULTURA DO MAMOEIRO
}

\author{
Mariana Lima de Jesus ${ }^{1}$ \\ Abel Souza da Fonseca ${ }^{2}$ \\ Alexandre Candido Xavier ${ }^{3}$ \\ Samuel de Assis Silva ${ }^{4}$ \\ Lucas Barbosa Laurindo 5 \\ Julião Soares de Souza Lima ${ }^{6}$
}

Resumo: Tendo em vista a importância do $\mathrm{N}$ e do $\mathrm{K}$ no fomento do crescimento vegetativo e do estádio de florescimento do mamoeiro e de sua influencia no equilíbrio nutricional da lavoura objetivou-se com esse estudo quantificar a variabilidade espacial dos índices DRIS do $\mathrm{N}$ e do $\mathrm{K}$ de mamoeiro produzido no norte capixaba e correlacionar linearmente e espacialmente seus valores com a produtividade e o índice de balanço nutricional da lavoura. O estudo foi realizado com dados de produtividade e de teores foliares (macronutrientes: N, P, K, Ca, Mg, S; e micronutrientes: Zn e Mn.) do pecíolo do mamoeiro de 129 pontos georreferenciados, de uma lavoura comercial de mamão, no município de São Mateus-ES. Esse teores foliares foram utilizados para calculo dos Índice DRIS e do índice de balanço nutricional (IBN). Os índices $D R I S$ do $\mathrm{N}$ e do K apresentaram dependência espacial, ajustando-se aos modelos exponencial e esférico, respectivamente. Apenas o IDK apresentou correlação linear com a produtividade.

Palavras-chave: Agricultura de precisão; Geoestatística; Carica papaya; Estado nutricional; DRIS.

\footnotetext{
1 Mestrado em Produção Vegetal/Universidade Federal do Espírito Santo, Brasil. E-mail: marianaldejesus@gmail.com.

2 Doutorado em Produção Vegetal/Universidade Federal do Espírito Santo, Brasil. E-mail: abelsouzafonseca@gmail.com.

3 Professor/Universidade Federal do Espírito Santo, Brasil. E-mail: alexandre.candido.xavier.ufes@gmail.com.

${ }^{4}$ Professor/Universidade Federal do Espírito Santo, Brasil. E-mail: samuel.assilva@gmail.com.

${ }^{5}$ Graduação emAgronomia/Universidade Federal do Espírito Santo, Brasil. E-mail: lucas.Ib12@hotmail.com.

${ }^{6}$ Professor/Universidade Federal do Espírito Santo, Brasil. E-mail: limajss@yahoo.com.br.
} 